УДК 338.242

ББК 65.050

РАЗВИТИЕ ОРГАНИЗАЦИОННО-ЭКОНОМИЧЕСКОГО МЕХАНИЗМА УПРАВЛЕНИЯ ФОРМИРОВАНИЕМ КЛАСТЕРНО-СЕТЕВОЙ СРЕДЫ В СФЕРЕ ИСПОЛЬЗОВАНИЯ ВТОРИЧНЫХ МОЛОЧНЫХ РЕСУРСОВ В РЕСПУБЛИКЕ БЕЛАРУСЬ

\author{
Е. И. БАХМАТОВА \\ ebakhmatova@mail.ru \\ старший преподаватель кафедры «Экономика и право» \\ Белорусский национальный технический университет \\ г. Минск, Республика Беларусь
}

В статье поднимается проблема необходимости стимулирования кластерно-сетевой стратификачии среды использования вторичных молочных ресурсов и ее естественной трансформации в устойчиво функционирующий кластер. Рассматривается получивший распространение в европейских странах, прикладной инструментарий повышения качества и сетевой связности деловой среды. Предлагаются направления развития организационно-экономического механизма управления формированием кластерно-сетевой среды в сфере использования вторичных молочных в Республике Беларусь. Приводится сравнительная характеристика запланированных государственными органами управления и предлагаемых для реализащии инструментов стимулирования кластерно-сетевой среды, как в иелом, так и в сфере использования вторичных молочных ресурсов.

Ключевые слова: кластерно-сетевая стратификация деловой среды, сетевые характеристики деловой среды, организационно-экономический механизм стимулирования кластеризации.

\title{
THE DEVELOPMENT OF THE ORGANIZATIONAL AND ECONOMIC MANAGEMENT MECHANISM OF THE FORMATION OF CLUSTER AND NETWORK ENVIRONMENT IN THE SPHERE OF SECONDARY DAIRY RESOURCES USAGE IN THE REPUBLIC OF BELARUS
}

\author{
E. I. BAKHMATOVA \\ senior teacher in the Department «Economics and Law» \\ Belarusian National Technical University \\ Minsk, the Republic of Belarus
}

The article rises the challenge in the need for the stimulation of cluster and network stratification of the environment of secondary dairy resources usage and its natural transformation into the sustainable cluster. Management tools to improve the quality and networking of the business environment applied in the European countries are considered. Directions to develop the organizational and economic management mechanism of the formation of cluster and network environment in the sphere of secondary dairy resources usage in the Republic of Belarus are offered. The comparative characteristic of the offered and planned by public authorities management tools to stimulate the cluster and network environment in general, and in the sphere of secondary dairy resources usage is given. 
Keywords: cluster and network stratification of the business environment, network characteristics of the business environment, organizational and economic management mechanism to stimulate cluster stratification.

\section{ВВЕДЕНИЕ}

Положительное влияние на потенциал кластеризации оказывает реализация государственной политики, направленной, главенствующим образом, на стимулирование и поощрение участия в кластерно-сетевых образованиях, а не предотвращение, препятствование или ограничение деятельности незаинтересованной части бизнес-сообщества. Перспективы для становления бизнес-сетей и дальнейшего формирования на их основе устойчиво функционирующих кластеров создает государственная политика, которая служит стимулом, побуждает, поощряет, поддерживает и содействует инновационно-интеграционным процессам. Стимулирующая государственная кластерная политика должна гарантировать установление тесных продуктивных взаимосвязей между разрозненными элементами экономической системы, равенство и взаимный учет интересов ее участников в процессе достижения общей цели экономического развития и индивидуальных конкурентных преимуществ каждого из них. При этом кластерная политика не должна носить селективный характер, должна быть общедоступной, положительным образом воздействовать на деловую среду функционирования акторов в целом, ее основу должны составлять организационные инструменты стимулирования информационнознаниевого обмена, а не архаичные инструменты финансирования или льготирования.

Разработка и применение организационно-экономического механизма повышения качества деловой среды - одна из приоритетных задач становления кластерно-сетевой среды использования вторичных молочных ресурсов и ее естественной трансформации в устойчиво функционирующий кластер. Запустить процессы сетевого межорганизационного взаимодействия централизованными решениями или путем применения архаичных инструментов конкурсного адресного финансирования, увеличения затрат на НИОКР или предоставления преференциальных режимов - невозможно. Для стимулирования интерактивных сетевых взаимодействий необходимы изменения деловой среды генерирования, обмена и применения знаний с целью повышения ее качества и придания ей сетевых характеристик организационной, информационной открытости, горизонтальной связности, инновационной восприимчивости, высокого уровня доверия и т. д.

Придание деловой среде сетевых характеристик, их поддержание и усиление ключевая задача реализации сетевой концепции на всех этапах кластерно-сетевой стратификации среды использования вторичных молочных ресурсов, решение которой требует от правительственных институтов применения абсолютно новых инструментов управления, выработанных на основе коллективного способа принятия решений и с учетом их систематической адаптации к изменениям внешней среды. В качестве наиболее целесообразных и результативных рассматриваются инструменты, стимулирующие комплементарный обмен знаниевыми и информационными активами, непрерывное коллективное генерирование и потребление пула новых знаний, развитие инновационной инфраструктуры, установление основанных на отношенческих контрактах взаимовыгодных партнерских взаимодействий. 


\section{РЕЗУЛЬТАТЫ И ИХ ОБСУЖДЕНИЕ}

Прикладной инструментарий повышения качества и сетевой связности деловой среды находится на этапе динамичного становления и опережает этапы его теоретического подкрепления. Применяемые в международной практике инструменты сетевой трансформации деловой среды чрезвычайно разнообразны, превалирующим образом носят организационный характер и включают: интерактивные и диалоговые платформы обмена информацией и знаниями в различных формах (конференции, рабочие группы, экспертные лаборатории, заседания, советы, семинары, творческие мастерские, форумы, выставки, встречи и т. д.), сетевое посредничество, сопроизводство, софинансирование, коспециализация, пиринг, форсайтинг, интернализация кластерных сетей и т. д. [1].

В европейских странах получает распространение подход, согласно которому инструменты повышения качества деловой среды дифференцируются в зависимости от стадии кластерно-сетевой стратификации и включают меры, направленные на: привлечение акторов и становление сетевого взаимодействия, продвижение сетевого взаимодействия и развитие комплекса коллективных услуг, становление и развитие коллаборации в рамках НИОКР и коммерциализации инноваций [2]. Данного подхода к разработке и применению механизма стимулирования предлагается придерживаться в процессе реализации сетевой концепции кластерно-сетевой стратификации среды использования вторичных молочных ресурсов в Республике Беларусь.

Стратегическую роль в процессах передачи и концентрации управленческого воздействия на основе инструментов стимулирования кластерно-сетевой стратификации играют институты поддержки сетевых взаимодействий и коллаборации - особые инфраструктурные организации-посредники, которые функционально нельзя отнести ни к одному из трех звеньев спирали Г. Ицковица. Создание такого рода инфраструктуры инициируют государственные органы управления, однако, в процессы организации и осуществления деятельности инфраструктурных посредников должны вовлекаться представители научной и бизнес-среды.

На сетевую инфраструктуру возложена ответственность за выполнение организационных, информационных, консультационных, координирующих, исследовательских функций, создания платформ для диалога. Инфраструктурные организации в целом должны содействовать становлению и укреплению системы межорганизационных связей, осознанию акторами преимуществ сетевого взаимодействия, повышению уровня доверия, информационной и организационной открытости, партнерскому сближению, достижению совместного видения, согласованной деятельности по продвижению проектов коллаборации и кластерных инициатив.

Становление кластерно-сетевой модели экономики требует от акторов деловой среды существенных прогрессивных изменений, процесс реализации которых не может происходить стихийно. Инструменты, применяемые на этапе вовлечения акторов в паттерны сетевого сотрудничества, должны быть направлены на привлечение внимания к проблеме и возможностям использования вторичных молочных ресурсов специалистов различного профиля и уровней управления, способствовать формированию устойчивой заинтересованности к возможностям повышения эффективности использования коммерческого и инновационного потенциала рынка вторичных молочных ресурсов, естественным образом содействовать постепенному преодолению феномена сопротивления новому.

На ранних стадиях становления кластерно-сетевой среды важнейшей проблемой сетевой стратификации выступает необходимость преодоления феномена сопротивления новому. Наиболее известные методы успешного управления изменениями, такие, как модель Л. Гейнера, метод адаптивных изменений И. Ансоффа, акцентируют основное 
внимание на необходимости обсуждения проблем и путей внедрения изменений со всеми участниками видоизменяемой системы управления. В контексте кластерно-сетевого развития инструментами одновременно информирования, привлечения внимания и управления сопротивлением изменениям являются интерактивные и диалоговые бизнес-площадки, которые могут быть реализованы в форме лекций, заседаний рабочих групп, советов, совещаний и т. д.

На этапе становления сетевой среды межорганизационных коммуникаций и информационного обмена ответственность за подготовку материалов и реализацию интерактивных площадок должна быть возложена на специфическое организационно-информационное звено - посредника-фасилитатора, функции которого должны выполняться совместно государственными органами управления, научными организациями, специалистами в области технологии пищевых производств, прогрессивными управленцами, экономистами, специалистами в области маркетинговых исследований, маркетинговых коммуникаций и т. д. Организации-фасилитаторы должны преследовать целью своей деятельности создание условий для неформальных коммуникаций, построения устойчивых сетей регулярного обмена рыночной и технологической информацией, идеями, знаниями, опытом и коллективного обучения.

Мероприятия информационного трансфера в рамках инициируемых организациями-фасилитаторами интерактивных площадок должны транслироваться онлайн, все обсуждаемые материалы должны быть доступны на специализированном интернет-ресурсе в формате видеозаписей, структурированных презентаций, полнотекстовых информационных баз. На специалистов организационно-информационного звена - фасилитаторов кластерно-сетевой стратификации должны быть возложены функции осуществления подготовки информационных и обучающих материалов, обзоров тенденций рынков, в т. ч. зарубежных, поиска стейкхолдеров, проведения информирования, лекций, тренингов, обучения специалистов, как на централизованных площадках, так и на рабочих местах.

Специалисты-фасилитаторы также нуждаются в предварительном комплексном обучении или повышении квалификации. Для реализации данной задачи необходимо разработать учебный план и учебные программы дисциплин с привлечением зарубежного опыта и специалистов-тьюторов. По мере формирования устойчивой заинтересованности акторов к возможностям использования потенциала рынка вторичных молочных ресурсов на основе сетевых взаимодействий, актуализации должны подлежать как программы обучения фасилитаторов, так и программы тренингов потенциальных участников сетевого сотрудничества.

На ранних этапах кластеризации экономики государственным органам управления особенно важно отказаться от осуществления конкурсных отборов и единоличного определения приоритетов развития и стремиться самостоятельно позиционировать себя как неотъемлемого равноправного участника кластерно-сетевых образований. Способность государственных органов управления одновременно участвовать в кластерном взаимодействии в качестве партнера и инспирировать его в целом имеет стратегическое значение на всех этапах кластерно-сетевой стратификации. В этой роли государственные органы управления должны, а содействовать акторам в поиске идей и партнеров коллаборации, поддерживать инфраструктуру развития сетевых и коллаборативных взаимодействий.

На этапе привлечения внимания и формирования заинтересованности акторов деловой среды использования вторичных молочных ресурсов результативными также должны оказаться действия государственных органов управления по реорганизации системы аккумулирования и представления информации. В Республике Беларусь широко распространена практика организации и представления статистической информации в разрезе регионов и отраслей национальной экономики. Как потенциальным участникам 
бизнес-сети, так и фасилитаторам кластерного развития важно иметь доступ к релевантной социально-экономической информации, сгруппированной в разрезе бизнес-сети. Такого рода информация может включать, уровень занятости, динамику объемов производства и реализации, запасов, финансовые результаты в отраслях - потенциальных участниках бизнес-сети, перечень технологий, поставщиков и потребителей, вакансии и предложения на рынке труда, проектные нормы и нормативы, технико-экономические обоснования, уровень патентной, инновационной активности и т. д.

Ограниченный доступ к лучшим мировым практикам ведения бизнеса, новым источникам знания и технологического опыта, что особенно характерно для переходных экономик, представляет собой существенный барьер для поиска и исследования перспектив реализации новых долгосрочных стратегических направлений развития организацийучастников кластерно-сетевой среды. Информационную замкнутость и ассиметрию позволяет в некоторой степени преодолевать расширенный доступ к соответствующим специализированным интернет-ресурсам и сервисам. Первостепенное значение имеет также предоставление фасилитаторам и потенциальным участникам бизнес-сети доступа к мировым базам социально-экономических индикаторов функционирования сетевых, кластерных образований, проектов коллаборации в аналогичных сферах деятельности за рубежом.

Ключевую роль в создании предпосылок для эффективного формирования портфеля инновационных идей и бенчмаркинга играет прямое межорганизационное взаимодействие. Фасилитаторы могут содействовать накоплению зарубежного опыта на основе организации международных выставок, узконаправленных деловых командировок, стажировок и т. д.

По мере преодоления феномена сопротивления новому и формирования устойчивой заинтересованности к возможностям использования коммерческого и инновационного потенциала рынка вторичных молочных ресурсов на основе развития межорганизационного взаимодействия, акторы деловой среды должны привлекаться к процессам генерирования идей сотрудничества, инициирования и информационного наполнения интерактивных площадок и специализированных интернет-ресурсов, что будет способствовать свободному обмену взаимной информацией и повышению уровня доверия внутри информационной сети.

Дальнейший этап продвижения сетевого взаимодействия и преобразования бизнес-сетей, основанных на понимании преимуществ неформальных бизнес-коммуникаций, в проекты коллаборации, потребует реорганизации инфраструктурной системы поставки услуг на основе создания нового информационно-консультационного звена - сетевых посредников. Как государственные, так и частные научно-исследовательские, инновационные, образовательные, консалтинговые, финансовые и прочие инфраструктурные организации зачастую осуществляют свою деятельность разрозненно, независимо друг от друга. В связи с этим, актуальность приобретает переориентация инфраструктурных организаций на проблемно-ориентированный подход, который опирается, прежде всего, на интересы участников кластерно-сетевой стратификации, а не только на достижение индивидуального коммерческого, социального, научно-технического или иного результата деятельности. Проблемно-ориентированный подход является обязательным условием эффективного вовлечения инфраструктурных организаций в кластерно-сетевые паттерны сотрудничества, т. к. предполагает делегирование им функции организатора исследовательско-аналитической работы.

Необходимые на этапе становления паттернов коллаборации преобразования могут быть достигнуты как на основе проведения стимулирующей разъяснительной работы среди персонала существующих организаций, так и путем создания новых специализро- 
ванных государственных инфраструктурных организаций - сетевых посредников - поставщиков широкого комплекса услуг участникам кластерно-сетевой среды. Комплекс услуг, поставляемых акторам деловой среды специализированными сетевыми посредниками, должен включать: предоставление доступа к базам данных потребителей, поставщиков, конкурентов, инноваций, патентов, конъюнктурной информации, маркетинговое исследование, консультирование, профессиональное обучение, экспертиза проектов, тестирование научных разработок и др. Особенно важно, чтобы сотрудники кластерно-сетевых инфраструктурных организаций-посредников имели производственный опыт, демонстрировали глубокое понимание проблем, технологий, рынков сбыта и потенциальных потребителей добавленной ценности, создаваемой участниками кластерно-сетевой стратификации.

Сетевые посредники как вид специализированных инфраструктурных организаций получает большую популярность в странах как развитых, так и переходных экономик. В Республике Беларусь, в частности, в соответствии с постановлением Совета Министров Республики Беларусь от 16 января 2014 г. № 27 «Об утверждении концепции формирования и развития инновационно-промышленных кластеров в Республике Беларусь и мероприятий по ее реализации» (далее Концепция) предусмотрено создание сети центров кластерного развития на базе облисполкомов, Минского горисполкома, объединений юридических лиц и (или) индивидуальных предпринимателей (ассоциации и союзы), а также наиболее развитых научно-технологических парков и иных организаций [3]. В соответствии с Концепцией, предметом деятельности центров кластерного развития будет являться сопровождение кластерных проектов посредством оказания организационных, информационных и аналитических услуг участникам кластеров, в том числе, оказание консалтинговых услуг (юридических, финансовых, инжиниринговых и других), поиск дополнительных источников финансирования для реализации кластерных проектов, разработка бизнес-планов, маркетинговые исследования, продвижение на рынок продукции участников кластера, организация конференций, семинаров и других информационных мероприятий для участников кластера, организация обучения и повышения квалификации кадров руководителей и специалистов участников кластера [3; 4]. Таким образом, в соответствии с Концепцией, центры кластерного развития должны представлять собой комплексные инфраструктурные организации, предоставляющие широкий перечень универсальных услуг участникам сформированных кластеров, не принимая во внимание сферу их деятельности. Позиция государственных органов управления, согласно которой инфраструктурные организации инновационного посредничества должны создаваться на этапе функционирования кластеров и предоставлять широкий спектр разнообразных услуг без учета сферы экономической активности их участников, заведомо малоэффективна.

Функцию поддержки конкретных проектов коллаборации и кластерных инициатив должны выполнять специализированные менторские организации - акселераторы. В отличие от сетевых посредников акселераторы должны поставлять широкий комплекс узкоспециализированных услуг конкретным проектам коллаборации и кластерных инициативам в особом диалоговом режиме и на принципах дизайн-мышления. В обоснование значимости данного института посредников отметим, что создание кластера часто сопряжено с вовлечением организаций в новые виды деятельности, которые требуют формирования и накопления технологического опыта. Поэтому информация и знания становятся ключевым фактором успеха. Кластерные инициативы могут извлечь значительные выгоды за счет потребления услуг узкоспециализированных организаций инновационного развития, продуктивность работы которых существенно повышается в случае участия в них существующих предпринимательских ассоциаций и союзов. 
В соответствии с Концепцией в Республике Беларусь предусматривается создание и организация деятельности рабочих групп для содействия формированию инновационно-промышленных кластеров в облисполкомах (Минском горисполкоме), в том числе с участием представителей указанных облисполкомов (Минского горисполкома), Министерства экономики, Государственного комитета по науке и технологиям, отраслевых министерств и концернов, бизнес-ассоциаций, на базе подчиненных организаций (участников бизнес-ассоциаций), в которых намечается формирование таких инновационнопромышленных кластеров [3; 4]. По своему функциональному назначению рабочие группы представляют собой конкретную форму бизнес-акселератора. Организация заседаний рабочих групп с участием представителей власти, науки и бизнеса является важнейшим мероприятием на этапе становления протокластерной среды, стимулирующим кластерную инициативу. В рамках заседаний рабочих групп обсуждение возможностей кластерно-сетевой стратификации среды использования вторичных молочных ресурсов должно проводиться на базе результатов совместных маркетинговых и кластерно-сетевых исследований.

На этапе продвижения коллаборации, возникновения кластерных инициатив следует расширить функции организаций-фасилитаторов, возложив на них ответственность за систематическое проведение мониторига условий функционирования протокластерной среды использования вторичных молочных ресурсов.

Инфрастурктурные преобразования касаются еще одной чрезвычайно важной компетенции госудраственных органов управления - целевой подготовки квалифицированных кадров. Исключая прогрессивную технико-технологическую и информационнознаниевую базу, для кластерно-сетевой стратификации нет ничего важнее полноценного кадрового резерва. В отношении никаких других видов ресурсов паттерны кластерносетевой стратификации не зависят так серьезно от государства, которое является самым крупным инвестором в сфере образования. В процессе принятия решения о кластерной инициативе бизнес оценивает доступ к трудовым ресурсам, которые обладают профессиональными компетенциями в соответствующих областях и в состоянии применить деловые навыки в особой рабочей среде кластера. В результате успех кластерной модели развития экономики ставится в прямую зависимость от способности учреждений образования быстро реагировать на появление потребности в специфических кадрах, сократить лаг с момента появления такой потребности и до момента ее удовлетворения.

В условиях кластерно-сетевого развития на первый план выходит целевая подготовка узкоспециализированных специалистов. Важным моментом также является применение междисциплинарных подходов, обеспечивающих преподавание дисциплин в контексте кластерной концепции развития экономики. Образовательные стандарты регламентируют порядок разработки и утверждения учебных планов специальностей часто без привязки к конкретной отрасли экономики. Между тем, получаемые знания и навыки в дальнейшем преобразуются с учетом отраслевых особенностей и могут значительно варьироваться по отраслям и секторам экономики. Проектирование учебных планов специальностей в разрезе отраслей-участников кластерно-сетевой среды создает хорошие перспективы для повышения уровня лояльности будущих специалистов и стремления развиваться профессионально в рамках бизнес-сетей, проектов коллаборации, организаций-участников кластера, а не пополнять ряды скептиков и становиться экономическими мигрантами.

Государственные органы управления должны способствовать установлению связей между учреждениями образования и инфраструктурными организациями кластерносетевого развития. Взамен ожиданию от учреждений образования своевременного и глу- 
бокого понимания кадровых потребностей участников кластерно-сетевой среды, государственные органы управления должны способствовать сотрудничеству университетов и фасилитаторов, сетевых посредников, акселераторов, которые, в свою очередь, должны выступать для учреждений образования ключевыми поставщиками самой актуальной информации о проблемах, потребностях акторов деловой среды, наиболее востребованных специальностях, определяя, тем самым, направления обновления образовательных стандартов, развития учебных планов и т. д. В свою очередь инфраструктурные организации кластерно-сетевого развития получат возможность постановки на научные основы процессов организации исследований бизнес-среды, формирования стратегических направлений деятельности, решения проблем и преодоления барьеров за счет привлечения профессорско-преподавательского персонала, организации на базе университетов практико-ориентированных площадок и т. д.

На стадии продвижения коллаборации и становления кластера большую актуальность также приобретет необходимость формирования развитых экспортных сетей. Существующие участники кластера, вступающие на различных уровнях в новые цепочки создания стоимости, могут испытывать затруднения в налаживании экспортных товаропроводящих сетей. Функция государственных органов управления в данном случае заключается в поиске партнеров на международных рынках, содействии формированию кластерных экспортных объединений.

Сравнительная характеристика запланированных государственными органами управления и предлагаемых для реализации инструментов стимулирования кластерносетевой среды, как в целом, так и в сфере использования вторичных молочных ресурсов, представлена в таблице 1.

Таблица 1 - Существующие и предлагаемые для реализации инструменты стимулирования кластеризации экономики

\begin{tabular}{|c|c|c|c|}
\hline \multirow{2}{*}{$\begin{array}{c}\text { Стадия кла- } \\
\text { стерно-сетевой } \\
\text { стратификации }\end{array}$} & \multirow{2}{*}{ Инструмент } & \multicolumn{2}{|c|}{ Содержание инструмента } \\
\hline & & запланированные & предлагаемые \\
\hline $\begin{array}{c}\text { становление } \\
\text { сетевой среды } \\
\text { межорганиза- } \\
\text { ционных ком- } \\
\text { муникаций и } \\
\text { информацион- } \\
\text { ного обмена }\end{array}$ & $\begin{array}{c}\text { развитие инновацион- } \\
\text { ной инфраструктуры } \\
\text { содействия кластериза- } \\
\text { ции экономики; }\end{array}$ & нет; & $\begin{array}{c}\text { создание специализирован- } \\
\text { ных инфраструктурных ор- } \\
\text { ганизаций -фасилитаторов, } \\
\text { способствующих становле- } \\
\text { нию устойчивых информа- } \\
\text { ционных сетей на основе ре- } \\
\text { гулярного обмена информа- } \\
\text { цией, идеями } \\
\text { и коллективного обучения; }\end{array}$ \\
\hline
\end{tabular}




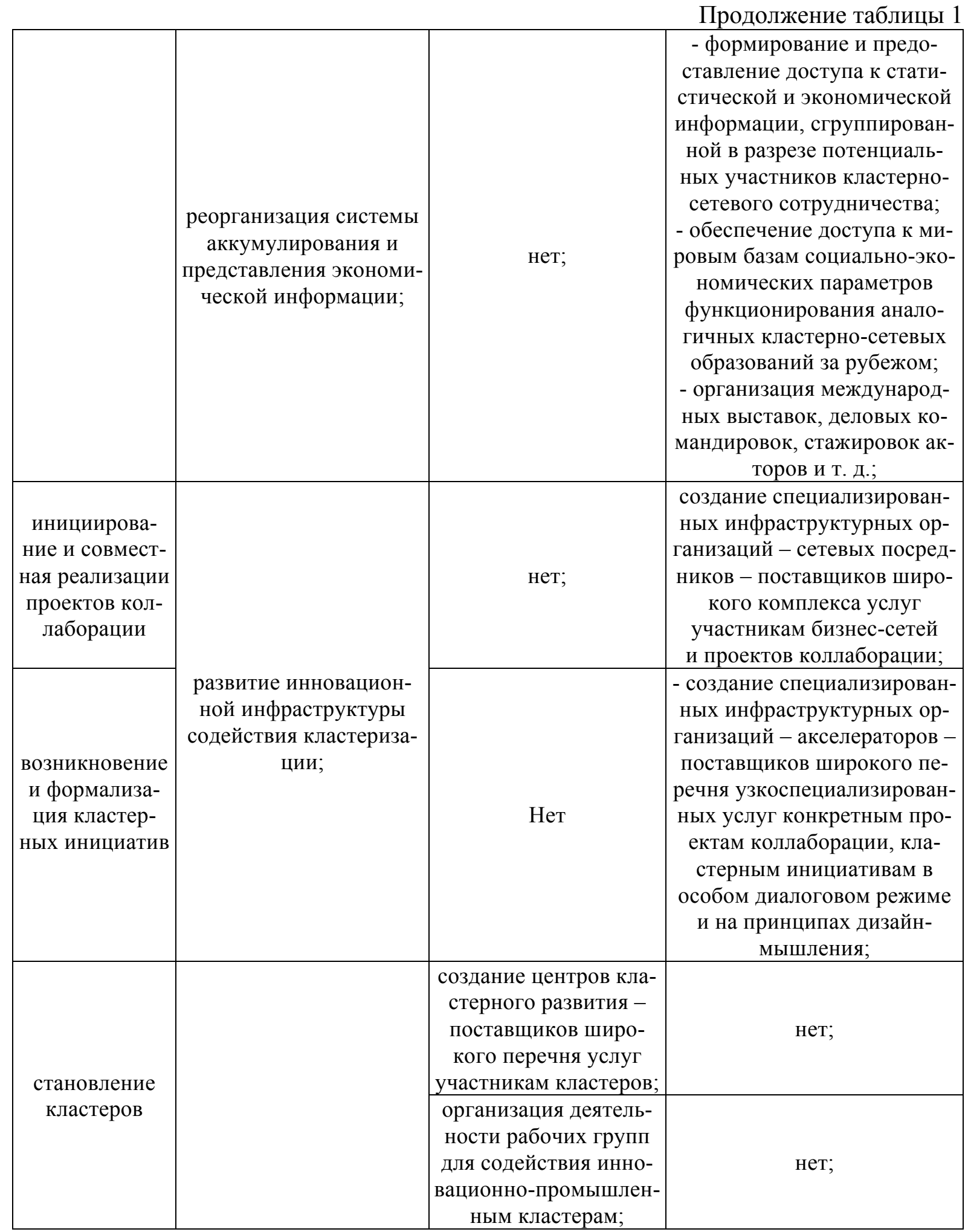


Окончание таблицы 1

\begin{tabular}{|c|c|c|}
\hline $\begin{array}{c}\text { государственная под- } \\
\text { держка }\end{array}$ & $\begin{array}{c}\text { - выделение на безвоз- } \\
\text { мездной и безвозврат- } \\
\text { ной основе субсидий } \\
\text { кластерным организа- } \\
\text { циям и центрам кла- } \\
\text { стерного развития на } \\
\text { разнообразные цели; } \\
\text { - конкурсные про- } \\
\text { граммы финансирова- } \\
\text { ния кластерных ини- } \\
\text { циатив, кластеров; }\end{array}$ & нет; \\
\hline $\begin{array}{c}\text { подготовка квалифици- } \\
\text { рованных кадров }\end{array}$ & нет; & $\begin{array}{c}\text { подготовка специалистов } \\
\text { в области кластеризации } \\
\text { экономики на базе учрежде- } \\
\text { ний высшего образования; }\end{array}$ \\
\hline \begin{tabular}{|c|} 
установление связей \\
между учреждениями \\
образования и центрами \\
кластерного развития \\
\end{tabular} & нет; & $\begin{array}{c}\text { - содействие сотрудничеству } \\
\text { университетов и инфра- } \\
\text { структуры кластерного раз- } \\
\text { вития; }\end{array}$ \\
\hline $\begin{array}{l}\text { формирование разви- } \\
\text { тых экспортных сетей }\end{array}$ & нет; & $\begin{array}{c}\text { поиск партнеров на между- } \\
\text { народных рынках и содей- } \\
\text { ствие формированию кла- } \\
\text { стерных экспортных объ- } \\
\text { единений. }\end{array}$ \\
\hline
\end{tabular}

Источник: собственная разработка на основе [3; 4].

Рекомендуемые для реализации инструменты управления кластеризацией по своему содержанию являются как экономическими, так и организационными, носят стимулирующий характер. Ключевое преимущество охарактеризованных выше и структурированных в виде таблицы 1 направлений развития организационно-экономического механизма управления кластеризацией заключается в создании возможностей для передачи и концентрации стимулирующего воздействия на не охваченных текущей кластерной политикой ранних стадиях кластеризации, имеющих стратегическое значение для реализации сетевой концепции кластерно-сетевой стратификации. Другие преимущества включают: направленность на содействие повышения качества деловой среды в целом на основе придания ей сетевых характеристик, общедоступность, дифференциация инструментов в разрезе стадий сетевой концепции кластеризации, создание предпосылок для формирования динамичной бизнес-среды непрерывных усовершенствований за счет увеличения плотности и интенсивности горизонтальных коммуникаций, стимулирования свободного обмена взаимной информацией.

\section{ВЫВОДЫ}

1. Запустить процессы сетевого взаимодействия на рынке вторичных молочных ресурсов централизованными решениями, селективным конкурсным предоставлением финансирования или преференциальных режимов - невозможно. Для стимулирования интерактивных сетевых взаимодействий необходимы изменения деловой среды использования вторичных молочных ресурсов на основе придания ей сетевых характеристик 
организационной и информационной открытости, горизонтальной связности, инновационной восприимчивости, высокого уровня партнерского доверия.

2. В целях развития запланированного для реализации в Республике Беларусь организационно-экономического механизма управления кластеризацией экономики, как целом, так и в сфере использования вторичных молочных ресурсов, предлагается:

- создать развитию инфраструктуру содействия сетевым взаимодействиям, коллаборации, кластерным инициативам и кластерам, включающую:

1) на стадии становления сетевой среды межорганизационных коммуникаций и информационного обмена - фасилитаторов, способствующих возникновению устойчивых информационных сетей на основе регулярного обмена информацией, идеями и коллективного обучения;

2) на стадии инициирования и совместной реализации проектов коллаборации сетевых посредников - поставщиков широкого комплекса услуг участникам бизнес-сетей и проектов коллаборации;

3) на стадии возникновения и формализации кластерных инициатив - акселераторов - поставщиков широкого комплекса узкоспециализированных услуг конкретным проектам коллаборации и кластерным инициативам в особом диалоговом режиме и на принципах дизайн-мышления.

- реорганизовать систему аккумулирования и представления рыночной, экономической, статистической, технологической информации путем ее систематизации в разрезе потенциальных участников кластерно-сетевого сотрудничества, а не сфер экономической деятельности или территориально-административных единиц;

- обеспечивать доступ акторам сетевой среды к мировым базам социально-экономических параметров функционирования аналогичных кластерно-сетевых образований за рубежом;

- способствовать организации международных выставок, деловых командировок, стажировок специалистов инфраструктуры содействия кластеризации и акторов сетевой среды;

- осуществлять подготовку специалистов в области кластеризации экономики на базе учреждений высшего образования;

- способствовать сотрудничеству университетов и организаций инфраструктуры содействия кластеризации;

- осуществлять поиск партнеров в сфере использования вторичных молочных ресурсов на международных рынках, иным образом содействовать формированию развитых экспортных сетей.

3. Особенности предлагаемых организационно-экономических инструментов по отношению к запланированным для реализации в Республике заключаются в следующем: нацеленность на повышение качества деловой среды в целом, а не формирование преференциальных режимов функционирования отдельных территорий, акторов или их групп на рынке вторичных молочных ресурсов; дифференциация организаций инфраструктуры содействия кластерному развитию и выполняемых ими функций в разрезе стадий сетевой концепции кластеризации.

4. Предлагаемые направления развития организационно-экономического механизма управления кластеризацией деловой среды использования вторичных молочных ресурсов в Республике Беларусь обеспечат: передачу и концентрацию стимулирующего воздействия на не охваченные текущей кластерной политикой ранние стадии кластеризации, имеющие стратегическое значение для реализации сетевой концепции кластерносетевой стратификации; доступность инструментов содействия кластеризации не только 
участникам кластерных инициатив или кластеров, но также и потенциальным, действующим участникам информационных, бизнес-сетей, проектов коллаборации; формирование на рынке вторичных молочных ресурсов в Республике Беларусь предпосылок для становления динамичной бизнес-среды непрерывных усовершенствований за счет увеличения плотности и интенсивности горизонтальных коммуникаций, стимулирования свободного обмена взаимной информацией.

\section{СПИСОК ИСПОЛЬЗОВАННЫХ ИСТОЧНИКОВ}

1. Technology and Industry Outlook 2012 «Cluster policy and smart specialization» [Electronic resource] // OECD Science. - Mode of access: http://www.keepeek.com/ Digital-Asset-Management/oecd/science-and-technology/oecd-science-technology-and-industryoutlook-2012_sti_outlook-2012-en\#.WLYaIfLojIU. - Date of access: 15.09.2018.

2. Competitive Regional Clusters. National Policy Approaches [Electronic resource] // United nations ESCAP. - Mode of access: https://artnet.unescap.org/tid/artnet/mtg/gmscb_ regionalclusters.pdf. - Date of access: 15.09.2018.

3. Об утверждении концепции формирования и развития инновационно-промышленных кластеров в Республике Беларусь и мероприятий по ее реализации: Постановление Совета Министров Республики Беларусь, 16 января 2014 г., № 27 // Нац. реестр правовых актов Респ. Беларусь. - 2014. - № 5/38322.

4. Крупский, Д. М. Руководство по созданию и организации деятельности кластеров в Республике Беларусь / Д. М. Крупский, А. Э. Омарова, Т. В. Хвалько // Совет по развитию предпринимательства в Республике Беларусь [Электронный ресурс]. - Режим доступа: http://ced.by/media/publication/books/rukovodstvo-klastery/rukovodstvo_po_sozdaniju_ klasterov_2.pdf. - Дата доступа: 15.09.2018.

\section{REFERENCES}

1. Technology and Industry Outlook 2012 «Cluster policy and smart specialization» [Electronic resource] // OECD Science. - Mode of access: http://www.keepeek.com/DigitalAsset-Management/oecd/science-and-technology/oecd-science-technology-and-industry-out look-2012_sti_outlook-2012-en\#.WLYaIfLojIU. - Date of access: 15.09.2018.

2. Competitive Regional Clusters. National Policy Approaches [Electronic resource] // United nations ESCAP. - Mode of access: https://artnet.unescap.org/tid/artnet/mtg/gmscb_re gionalclusters.pdf. - Date of access: 15.09.2018.

3. $\mathrm{Ob}$ utverzhdenii koncepcii formirovaniya i razvitiya innovacionno-promyshlennyh klasterov v Respublike Belarus' i meropriyatij po ee realizacii: Postanovlenie Soveta Ministrov Respubliki Belarus', 16 yanvarya 2014 g., № 27 // Nac. reestr pravovyh aktov Resp. Belarus'. 2014. - № 5/38322.

4. Krupskij, D. M. Rukovodstvo po sozdaniyu i organizacii deyatel'nosti klasterov v Respublike Belarus' / D. M. Krupskij, A. Eh. Omarova, T. V. Hval'ko // Sovet po razvitiyu predprinimatel'stva v Respublike Belarus' [Ehlektronnyj resurs]. - Rezhim dostupa: http://ced.by/media/publication/books/rukovodstvo-klastery/rukovodstvo_po_sozdaniju_klas terov_2.pdf. - Data dostupa: 15.09.2018.

Статья поступила в редакичию 2 октября 2018 года. 